\title{
Why quest to modern energy urge to rural household: implication to mitigate climate change and food insecurity, Northern Ethiopia
}

Daniel Assefa ( $\nabla$ danasse19@gmail.com )

Ambo University https://orcid.org/0000-0002-1854-9830

Kebede Wolka

Hawassa University

Teshale W/amanuel

Hawassa University

Original article

Keywords: Food security, Modern energy, Traditional energy

Posted Date: November 8th, 2021

DOl: https://doi.org/10.21203/rs.3.rs-1009829/v1

License: (c) (i) This work is licensed under a Creative Commons Attribution 4.0 International License.

Read Full License 


\section{Abstract}

\section{Background}

Energy is a key factor of socio-economic development. Currently, however, millions of people across the world suffer from energy poverty, having little or no access to energy for cooking, lighting, heating, cooling or using information and communication technology. As a result this study was aimed to investigate the domestic energy sources for households and the impact of biomass use as a source of energy on the environment, and food insecurity in North highland of Ethiopia. A total of 398 heads of households were interviewed individually using structured questionnaire, whereas 16 focus group discussions and 12 key informant interviews were conducted using discussion guiding checklist. Descriptive data analysis techniques were used to analyze quantitative data while content analysis method was used to analyze qualitative data.

\section{Result}

The use of traditional fuel such as fire wood, charcoal, crop residue, animal dung, leaves, and any biomass residue that can be combusted were used as energy sources in the area, which aggravate degradation of agricultural land. The move towards the adaptation of modern energy sources was not common because of many barriers such as lack of finance (98\%), access (97\%), durability (97\%) and lack of awareness (93\%). The findings showed that land degradation has been severe to the extent that no grains can be collected from crop production. As a result, people were exposed to both chronic and transitory food insecurity and hence the majority of people make their living on food aid.

\section{Conclusion}

This calls for minimizing land degradation by introducing alternative energy sources to the households. In this regard, technology developers, bilateral organizations and NGOs can play their role to promote alternative modern energy technologies that are easy accessible both in terms of availability and affordability, and operable by rural people.

\section{Introduction}

Energy is a key factor of socio-economic development (UN, 2012). Currently, however, millions of people across the world suffer from energy poverty, having little or no access to energy for cooking, lighting, heating, cooling or using information and communication technology. This has a detrimental impact on their quality of life, access to clean water, health and opportunities to gain an education, and increasing agricultural productivity and earn income (Zereay, et al., 2013; BMZ, 2014). The depth of energy poverty is severe especially in developing countries, where the availability of energy is limited or economically unaffordable (Quitzow, et al., 2016). 
Currently, about 1.1 billion people, $14 \%$ of the population, in the world have no access to electricity (UNCTAD, 2019). Most of them are predominantly situated in rural areas of Sub-Saharan Africa, where biomass still constitutes the main source of energy (Gray, et al., 2018). Sub-Saharan Africa is the most electricity-poor region in the world: more than 600 million out of 950 million people lack access to electricity, and several million people are connected to an unreliable grid that does not meet their daily energy service needs (Avila, et al., 2017). Those authors also reported that most of the countries in this region have average electricity access rates of about $20 \%$, and two out of three people lack access to modern energy services (Avila, et al., 2017). In this region, two-thirds of its total energy use occurs in the residential sector, most energy is used for cooking, and dominated by traditional biomass (86\%) (IEA, 2014). In Ethiopia, domestic energy requirements of rural and urban areas are mostly (about 90\%) met from wood, animal dung and agricultural residues (FDRG-MoWE, 2012). By 2014, the country's overall electrification rate had reached just $23 \%$, leaving majority of the population without a connection to grid (Barnes, et al., 2016).

Biomass energy is a traditional source of energy, which refers to a wide range of natural organic fuels such as wood, charcoal, agricultural residues and animal waste, is often used in its traditional and unprocessed form (Karekezi \& Kithyoma, 2003). The main energy demand in rural areas of low income countries is for cooking and the main source of fuel for satisfying this demand comes from traditional sources of energy: fuel-wood, dung, and agricultural residue, which are highly inefficient, polluting, and adversely affect environment and land productivity (World Bank, 2000; Karekezi \& Kithyoma, 2003; Tucho and Nonhebel, 2017). Use of biomass for energy; to cook meals and heating homes, exposes rural people and their families to hazards of smoke and fumes. In fact, the indoor air pollution associated with biomass use is directly responsible for more deaths than malaria in most parts of developing countries (Kibria, 2015). When burned, traditional fuels often produce hazardous chemicals with negative health impacts, especially when used indoors (UNCTAD, 2010). Indeed, over a million of deaths a year due to lack of access to electricity, safe heating, and cooking didn't receive sufficient attention compared to greenhouse gas emissions mitigation (Howells \& Alexander, 2012).

Economic poverty and dependence on traditional sources of fuels would go hand in hand. As household incomes rise, probability to switch to modern fuels is assumed very high, if these are available (Cherni, 2008). Most rural societies experience limited access to modern energy services, due to problems of either availability or affordability (UNCTAD, 2010). Lack of financial capacity to use new energy technology hinders the need by poor households live especially in developing countries like Ethiopia. That is why the majority of their people predominantly relay on traditional fuels (World Bank, 1996). On the other side, most developed countries and in the few cities of developing countries the energy that we consume today comes from energy sources that are expensive, highly polluting and non-sustainable in their nature (Dawit, 2010). Generally, either it is due to from traditional biomass or fossil fuel, the energy sector accounts for $65 \%$ of total global greenhouse gas (GHG) emissions (Vezzoli, et al., 2018).

Solving the problem related to energy sector is of vital importance to the environment, the global society and the world economy. Switching the energy use from traditional biomass towards alternative energy 
sources is part and parcel of solution and solving energy sector problem and rural poverty. The reliance on biomass for fuel lead to deforestation and land degradation that is the major cause for low crop productivity and result on rural food insecurity. The urgency to shift energy use towards modern sources is not only because of its impact on the environment, economy, and social wellbeing but the current capacity of traditional biomass is no longer sufficient to satisfy the fuel demands. Hence, decision to shift from traditional energy system to modern is a must. The modern energy sources that attracted special attention includes electricity, natural gas, clean cooking fuels and mechanical power that contribute to safe human well-being (Modi, et al., 2005). These are among advantages drive the world society fast toward renewable energy technologies to support the local development by reducing the burden of energy need on the biomass and a clean energy economy to prevent the dangerous warming of our planet (Vezzoli, et al., 2018).

To catch this benefit, the African countries have a titanic potential to generate modern energy from sources. Most African countries are gifted with a gigantic and still untapped renewable energy potential (Hafner, et al., 2018). Estimates of power generation potential in the continent are $350 \mathrm{GW}$ for hydroelectric, $110 \mathrm{GW}$ for wind, $15 \mathrm{GW}$ for geothermal and an amazing $1000 \mathrm{GW}$ for solar (African Development Bank, 2017). Potential for bioenergy is also high, with wood supply from surplus forest estimated at $520 \mathrm{GWh}$ /year (International Renewable Energy Agency, 2015). Solar energy potential is also particularly promising: although with varying potentials because of its geographical distribution, this type of energy could be harnessed virtually everywhere in Africa. These modern energy sources has also a wide range of advantages and it cause very little environmental impact and in most cases their social impacts are rated low (Dawit, 2010). Besides, they are also capable to provide energy services, including lighting and electricity, heating and cooling, mechanical energy and mobility (Sawin, et al., 2016).

Access to modern energy services and electricity is low in many developing countries, particularly in Africa. To achieve sustainable development goal with respect to energy, increasing access to energy for domestic use; essentially increasing access to technologies which use modern fuels or make use of traditional fuels in cleaner, safer and more environmentally sound ways and increasing access to electricity are essential (UNCTAD, 2019). Moreover, if the world is to develop sustainably, it will be necessary to secure access to affordable, reliable, sustainable, and modern energy services while reducing greenhouse gas emissions and the carbon footprint of the energy sector (Mazzoni \& Memon, 2003). In most jurisdictions, these socio-economic benefits are a major force driving policymakers to adopt renewable energy targets and support policies. This goal is now moving the world away from the consumption of fossil fuels, which cause climate change and other environmental and social challenges, toward cleaner, renewable forms of energy sources (Sawin, et al., 2016).

In contrast to untouched potential and the whim, the move to shift from traditional fuel use to modern renewable energy sources is very limited in Ethiopia. From the sustainable development perspective, a renewable and sustainable energy expansion needs to increase the availability of energy services to groups that currently have no or limited access, particularly to those in rural areas and those without connections to the grid (Sathaye, et al., 2011). In this regard, numbers of study were conducted focused 
on energy but no study has been done with the emphasis of energy sources and use in connection with food insecurity, climate change, and sustainable development. Therefore, the main reasons that initiated this research were: [1] Use of biomass for traditional fuel without setting pertinent attention for replacement to land cover change and causing soil erosion and land degradation. [2] existence of deep rooted food insecurity due to land degradation; [3] Most of the energy consumption is from fuel wood causing significant deforestation; [4] Huge numbers of poor depend on food aid instead of producing surplus yield due to low productivity of land caused by loss of soil fertility; [5] Inefficient cooking stoves have caused wastage of a lot of energy and exacerbates deforestation; and [6] High consumption rate of fuel wood due to absence of affordable alternative energy sources for people in the study site.

This study was conducted to answer (I) How much is the dependence of rural household on biomass for fuel affected the forest resources? (II) What is the implication of biomass energy utilization on household food insecurity? (III) How the use of traditional fuel to fulfill the energy need contributes for climate change? (IV) What are the barriers that affect the willingness to adopt modern energy technologies? and (V) How the use of traditional fuel impacts the path to ensure sustainable livelihood in the northern highland?

\section{Research Methodology 2.1. The study area}

The study was conducted in the northern highland of Ethiopia particularly in the two zones namely North Wollo and Wag Hemra zone. Geographically, North Wollo zone is located between $11^{\circ} \mathrm{N}$ to $12^{\circ} \mathrm{N}$ latitude and $39^{\circ} \mathrm{E}$ to $40^{\circ} \mathrm{E}$ longitudes and has an estimated area of $1,275,514.35$ hectares, which covers about 20 percent of the region (Eshetu, et al., 2017). Weldiya is the zonal capital town which is at about $521 \mathrm{~km}$ from Addis Ababa. Most of this zone is mountainous and characterized by steep slopes, which are unsuitable for agriculture and severely limits crop growth. Earlier survey reported that $24 \%$ of the land is arable, $4.6 \%$ pasture, $0.37 \%$ forest, $17.4 \%$ shrub land, $47.3 \%$ degraded or unusable, and the remaining $6.3 \%$ all other uses (Seid, 2002). According to the CSA (2017), the current total population of North Wollo zone is $1,824,361$ ( $50.1 \%$ male and $49.9 \%$ female); with an area of $12,172.50 \mathrm{~km}^{2}$ (CSA, 2013). From the total of eight districts in the zone, Lasta district was specifically selected for this study. Its major town is Lalibela, known for its monolithic churches, a UNESCO registered heritage. The area is generally classified as one of food insecure zones of the region, with a long history of food aid distributions (EEP, 2016).

Wag Hemra zone covers $9,039.04 \mathrm{~km}^{2}$ with $51 \mathrm{~km}^{2}$ of density in the square kilometer. Based on the CSA (2017) estimation the current total population of Wag Hemra zone is 351,905 (50.1\% male and $49.9 \%$ female) (CSA, 2013). Of the six districts in this Zone Sekota Zuriya district was explicitly selected for this study. The district is located between $12^{\circ} 23^{\prime}$ and $13^{\circ} 16^{\prime} \mathrm{N}$ latitudes and $38^{\circ} 44^{\prime}$ and $39^{\circ} 21^{\prime} \mathrm{E}$ longitudes (Getachew, et al., 2018). Sekota town (the capital of the district), which is also the capital of the zone, is 
$720 \mathrm{~km}$ North of Addis Ababa and $540 \mathrm{~km}$ north east of the regional state capital, Bahir Dar (BoFED, 2013).

\subsection{Sampling procedures}

Both probability and non-probability sampling procedures were used. First, North Wollo and Wag Hemera zones were purposively selected based on the dependence of biomass energy and the severity of land degradation and food insecurity. Secondly, the two districts, Lasta from North Wollo and Sekota from Wag Hemera zone were also purposively selected. Thirdly, a total of eight Kebeles (smallest level of government administrative units in Ethiopia) four from each district: Genetemariam, Erfa, Bilibala and Yimrhane-kristos from Lasta district and Wollehi, Abiya, Fiqreselam and Tsemera kebeles from Sekota district were randomly selected. Finally, respondents were selected for focus group discussion (FGD) and independent groups of elders, women and youth were selected for the discussion. Whereas, elders, religion leaders, experts, and development agents were purposively selected and used for key informant interview (KII). A total of 398 respondents were randomly selected from 79,058 households using Yemane (1967) formula $n=N / 1+N\left(e^{2}\right)$ at $5 \%$ and interviewed. The district level offices and departments visited for secondary data. The FGDs were held with 8-12 participants. The moderator facilitates the discussion using guiding open ended questions focusing on source of energy and associated challenges. In general, two FGDs were held in each kebele and the total of 16 FGD and 12 KII were contacted.

\subsection{Research approach and design}

Mixed approach of the research along with the phenomenological design was used to address the objectives of this study. The method employs both approaches iteratively or simultaneously to create a research outcome stronger because the combined quantitative and qualitative methods enable exploring more complex aspects and relations of the human and social world (Malina, 2010). Besides, it is very suitable approach to any given research project, its use would yield positive benefits, in that the use of differing approaches has the potential to provide a greater depth and breadth of information which is not possible utilizing singular approaches, qualitative or quantitative, in isolation (Almalki, 2016). Here in addition to quantitative approach qualitative methods also acquired relative emphasis in this study. This is because qualitative approach helps to conduct an in-depth study of social and cultural phenomena and focuses on text depending on the observations and descriptions (Myers, 2009). Qualitative approach is included here mainly to describe and interpret issues or phenomena systematically from the point of view of the individual or population being studied. Moreover, qualitative approach is an exploratory type of research, and seeks to explain 'how' and 'why' a particular social phenomenon, or program, operates as it does in a particular context. With this it tries to help us to understand the social world in which we live, and why things are the way they are (Polkinghorne, 2005).

On the other hand, Phenomenological design was used to frame the research and then to explore people's everyday life experience directly related with the environment. Phenomenology is used when the study is about the life experiences of a concept or phenomenon experienced by one or more individuals (Mohajan, 2018). In a qualitative types of research its broad importance is that it attempts to understand how 
participants make sense of their experiences (it does not assume that participants' accounts refer to some verifiable reality) but it recognizes that this involves a process of interpretation by the researcher (Hancock, et al., 2009). This is why it defined as an interpretive process in which the researcher makes an interpretation of the meaning of the lived experiences (Cresswell, 2007). To understand the live experience of the individuals and phenomenon under study facts from the individuals involved in the study gathered using an appropriate methods and tools.

Accordingly, the required qualitative and quantitative data were captured using appropriate methods and tools. While FGD, KII, and field observation were used to gather qualitative data with the help of discussion and in-depth interview guiding checklist, a household survey was employed to collect figurative data with structured questionnaire.

\subsection{Analysis}

Statistical Package for Social Science (SPSS) version 20 software was used to analyze data. Unpackaged voice data first transcribed and transformed in to verbal or text forms of data. The transcribed data were subject to categorization. Reading and re-reading of the text (transcribed data) to identify themes or patterns (i.e., ideas, concepts, behaviors, interactions, etc) and organize them into coherent categories that summarizes the whole data were carefully undertaken. Categorization is central steps of analysis in the hunt to meaning for different words and phrases through bringing together a number of observations, ideas and concepts which we consider similar in some respects, by implied contrast with other ides, concepts or observations (Dey, 1993). Finally, content analysis was used to produce this report. The advantage of content analysis is that it involves counting the frequency of occurrence of particular words, phrases, or concepts to summarize the whole text data and helps to produce a meaningful report (Hancock, et al., 2009).

\section{Result and discussion}

\subsection{Livelihood strategies of the community}

From focus group discussion and field observation, it was learned that, in the study area, crop-livestock mixed farming is the main means of living Crop production takes the highest land share because of land scarcity and economic capacity to own animals. Even though crop production was more practiced, it does not satisfy their annual food demand and thus, they rely on external food aid (Assefa, et al., Submitted). Teff, sorghum, and maize were the most major crop types, and cattle, goat, sheep, donkey, and poultry are commonly reared livestock.

\subsection{Domestic energy sources of the rural household}

From the focus group discussion and observations in the area, it was evident that biomass is the highest source of energy on which the entire rural households rely. All the respondents $(100 \%)$ reported that fire wood is used as a fuel for cooking, lighting and heating purposes. Although the extent is very low, they support their energy need with animal dung (85.49\%) and crop residue (83.55\%) for cooking, and some 
also use kerosene (46.09\%) and only $4.09 \%$ use small scale alternative energy sources like solar for lighting. Besides, very few, $4.57 \%$ of the respondents indicated that they use charcoal for heating and rarely use for coffee ceremony and majorities prepare and sell it to the urban residents (Table 1). Cooking was done primarily by firewood, and followed by animal dung and crop residues. Crop residue was used especially in the dry season at the time of harvesting period. Modi, (2004) found that poor individuals without access to modern energy source rely on traditional energy such as fuel wood and charcoal, which lead to environmental degradation such as desertification and soil erosion. In Ethiopia, studies showed that, the share of traditional biomass fuel (i.e., in the form of wood, charcoal and dung) accounts $~ 90 \%$ of total primary energy use of the household (Mekonnen and Kohlin, 2009), and about $84 \%$ and $99 \%$ of urban and rural households, respectively, rely on biomass as their primary fuel for cooking (Gurmessa, 2010). The practice was also common in many Sub-Saharan Africa, example, in Zambia where fuel wood is used for cooking and heating by $97 \%$ of rural and $85 \%$ of urban households (Central Statistics Office, 2005), and generally it is the major source of energy and contributing to over $70 \%$ of the total national energy budget (GRZ, 2007).

Table 1

Domestic energy sources on which rural households relied

\begin{tabular}{|llll|}
\hline Domestic energy sources & $\begin{array}{l}\text { North Wollo } \\
(\mathbf{n}=215)\end{array}$ & $\begin{array}{l}\text { Wag Hemera } \\
(\mathbf{n}=183)\end{array}$ & $\begin{array}{l}\text { Average } \\
(\mathbf{n}=398)\end{array}$ \\
\cline { 2 - 4 } & $\%$ & $\%$ & $\%$ \\
\hline Fire wood & 100 & 100 & 100.00 \\
\hline Dung cake & 84.19 & 86.79 & 85.49 \\
\hline Crop residue & 85.12 & 81.97 & 83.55 \\
\hline Charcoal & 3.09 & 6.05 & 4.57 \\
\hline Kerosene & 47.91 & 44.26 & 46.09 \\
\hline $\begin{array}{l}\text { Small scale of alternative energy technology } \\
\text { (Solar or electricity) }\end{array}$ & 3.26 & 4.92 & 4.09 \\
\hline Sources: Own survey & & & \\
\hline
\end{tabular}

The high dependence of rural households on traditional fuel was mainly associated to the economic development level of the country and settlement pattern of the community. Despite the technology advancement in alternative energy sources, the practice of using it was not considerable in the area. Moreover, FGD discussants said that the use of forest as main source of domestic energy has attained difficult state. On one hand, forest/woodland has been declining progressively compared to the situation in past (30-40 years ago). Musa and Azare (2016) indicated that in the past, the source of fuel wood was simple, and the environmental impacts arising from its exploitation were minimal due to low human 
population, however, as a result of population increase, dependence on wood as a source of fuel started showing signs of inadequacy.

On the other hand, the discussants explained that cutting tree for fire wood adversely affect land productivity and food security due to solemn degradation since tree and their emendate environment are the main sources of their livelihood. Even due to the previous unwise act, the community has been observing severe drought and loss of their livings including damage on their land. Replanting and growing tree will not be as easy as utilizing tree as the semi-arid environmental situation challenge growth. Dawit (2010) also noted that the huge amount of wood consumption, especially in the rural areas, is a catastrophic to the environment as tree plantation to replace them is not so common. The resulted deforestation that has been going on for many decades is also a cause to biodiversity loss and soil erosion which in turn affects the balance of the ecosystem. Generally, the upturning cumulative impacts of using traditional biomass as energy source on the livelihood and both rural and urban human wellbeing appear as the main insistent factor to switch from traditional energy source to modern sources but net yet.

\subsection{Effects of rural household dependence on biomass for fuel on forest resources}

The impacts of historical droughts, domestic consumption of tree, population growth, natural and accelerated aridity of the land, and the impact of current climate change were noted as the key reasons for the existing poor coverage of forest in the area. Discussants said that the communities were severely maltreated by droughts occurred in 1955, 1965, 1975, 1985, 1995, 2005 and 2015. Of these, although all the mentioned had caused comparable and continued impact on the community, the 1985 drought was caused the most severe impact on the human lives and forest resource. Dryness of trees and consequent depletion of natural resource including the fertile topsoil and the consequent poverty were among the most mentioned.

All the respondents (100\%) and discussants stated human contribution for the clearance of tree outweigh than the impact of drought (Figure 1). Although cutting trees for fire wood, house construction and other forest product like timber causes deforestation, conversion of forest land into cultivated land is also important cause of deforestation (FAO, 2016), which increase erosion, land degradation, biodiversity loss, food insecurity and poverty (FAO, 2017). Understanding the multiple side effects of deforestation on human life including local energy supply, there is growing interest to rehabilitate the area through massive plantation by government and non-government organizations. Despite natural and accelerated aridity that hinders the growth of forest biomass, dependence for fuel appeared as serious problem for an effective rehabilitation in the study area. Globally, enduring dependence of energy on fire wood for cooking, heating and lighting was added additional burden on land rehabilitation and poverty reduction efforts. FAO, (2017) stated that limited availability of, and access to fire wood fuel could exacerbate hunger and poverty by challenging the primary energy source for various purposes including cooking. 
The impact of energy problem moves from environmental and economic to social, example, through imposing women to move long distant to collect fire wood. Mazzoni, et al., (2003) stated that traditional fuel use has disproportionate effects on women, and contributes further to the social inequalities that are, for instance, caused by an uneven distribution of fuel-collection, cooking, and childcare responsibilities between men and women within the household. Of all these, the worst situation was the lack of no progress to switch from relying on traditional energy, which reached to no capacity to offer needed service, to alternative energy source. Because, in the nearby area, there were no forestlands from which the people could access fire wood easily though less recommended. Thus, community more rely on the animal dung and crop residue, which have still its own effect on the efforts to ensure food security.

\subsubsection{Effects of biomass fuel utilization on agricultural production}

Cutting tree for domestic energy source such as for fire wood and charcoal were among the key causes for the continued removal of forest resource and resultant low soil fertility, $100 \%$ of the respondents reported (Figure 1). Demands of fuel increase due to ever growing population that relies on biomass for fuel. In urban areas, where alternative energy such as electricity is available, due to cultural background and cost, Ethiopians prefer charcoal for cooking and heating. This adds to deforestation and land degradation through soil erosion and wind. In the study area, due to severe shortage of wood, animal dung has been used as energy sources for cooking, which should have been utilized for fertilizing cropland. Studies showed that cattle dung contains essential nutrients such as potassium, phosphorus and nitrogen and organic carbon, which have significant role on soil fertility (Nyamangara et al., 2001; Lakasi et al., 2003; Negasa et al., 2017). Thus, utilization of cattle dung for energy could adversely affect crop production.

In the study area, farmers use crop residue, mainly residue of maize and sorghum for fuel, and residue of crops such as teff is used for feeding livestock. From nutrient recycling and maintaining soil quality and reducing erosion perspectives, keeping residue on cropland is important (Turmel et al., 2014). Thus, removing residue, e.g., for fuel could affect cropland productivity and food security. As a result the farmers live in impoverished situation due to presence of both acute and transitory poverty. Because, the effects of degradation on land productivity; agriculture and livestock production had a negative effect on livelihoods of the community (Habtamu, et al., 2015). Biomass of the study site was highly impacted by repeatedly occurred severe drought, traditional farming practice and energy utilization pattern. The biomass production of the area is not sufficient to provide enough feed for livestock.

Discussants explained that land is being infertile and they could not be able to cover the consumption need of the household. About $97 \%$ of the surveyed households relate low productivity with loss of tree cover, which has several environmental benefit including erosion reduction and climate control, as they expressed (Figure 1). Deforestation causes drought and flooding, among others, leading to a decline in agricultural yields and food security (Berhanu, et al., 2017). 
Utilization of biomass for energy could have multiple effects on livestock production. Accordingly, about $95 \%$ of surveyed respondents reported that the present energy need for fire wood has been provoking the challenges of livestock production and productivity in many dimensions such as loss of grass; increase the prevalence of disease, and access to water (Figure 1). Land degradation due to forest could reduce availability of forage and water. That means, farmers were facing stern challenge to found pasture and water for their animals. While challenge for grass was due to couple of problems such as land degradation and sacristy of grassing land, accessibility of water especially during the dry season was mainly due to land degradation that caused by clearing tree or due to the biomass was destroyed. The perceived climate change due to deforestation and land degradation could be less suitable for livestock. Example, temperature affects most of the critical factors of livestock production, such as water availability, animal production and reproduction, and animal health (mostly through heat stress) (IPCC, 2019). This created favorable conditions for the occurrence of animal disease and affected the health of livestock. Rojas-Downing, et al., (2017) livestock diseases are mostly affected by increases in temperature and precipitation variation. Due to various infectious animal diseases caused by climate change, farmers lost their livestock and pressurized to have only few, affecting their livelihood.

Water availability of the area is low, particularly in dry season, which is associated to increased surface runoff in rainy season resulting from land degradation due to, partly, removing forest and other biomass for fuel. In this regard, about $87 \%$ of informants reported access to water was the pressing challenges in the area, which was due to primary dependence of the rural dwellers for wood on biomass (Figure 1). FAO (2015) stated that forests play a crucial role in the partitioning of water into surface flow, subsurface flow, and evapotranspiration. In contrast, the removals of forest and other biomass strongly impair the hydrological functioning of the environment (Todd-Brown, et al., 2013). Thus, discussants explained that due to land degradation ponds and water points were progressively dried up in the area. Reis-Pereira, et al., (2014) and Chakravarty, et al., (2012) pointed out that any change in the original land use can result in significant alterations of the water balance components of a watershed.

The observed scarcity of water in the area affected their live in various aspects: farmers were pressed to travel distant area in search of water for their livestock and domestic consumption especially by women. It added double burden on the farmers' livelihood through sharing their precious time and affecting their health. Water shortage affects crop production and livestock.

\subsubsection{Implication of biomass energy utilization on household food insecurity}

In the study area, there has been chronic food insecurity for more than three decades (Assefa et al., submitted). Focus group discussants and $98 \%$ of surveyed households indicated that land degradation partly due to utilization of biomass (fuel wood, charcoal, crop residue and animal dung) for energy contributed to the existing nasty food insecurity. As a result, farmers' ability to feed own household from self-production was very low, which might be not more than six months per year. The remaining months would be covered by donor based food aid, in the area, which was the long-existed trend In particular, 
following the Great Ethiopian Famine of 1984-1985, for example, more than 5 million people, majority are from northern region, have received food aid in the country on annual basis, indicating a situation of chronic food insecurity (Aschale, 2012). The land degradation, partly, due to back warded biomass energy utilization contributes for food insecurity.

The constant supply of food aid for the poor farmers with the aim of filling the yearly food gap had been passed two periods. Before 2005 the support of food was offered with the central aim of humanitarian act, since that time the support was shaped to developmental forms. On the other word, the previous cater of food for the needy people in the area was primarily initiated by natural event mainly drought but the revised forms of support of food aid was aimed to reduce food insecurity through the developmental activities like watershed management practices through the model of food-for-work. In the revised approach of food aid the eligible household, 'poor-of the-poor, could receive aid up on participating on developmental activities such as watershed management, which supposed to restore degraded land and perhaps improve the biomass energy supply. The food-for-work approach received great attention due to growing government, NGOs and development partners' interest to restore degraded landscape.

Environmental rehabilitation as a strategy for delivering food relief seemed a good approach of using relief to development, but the productivity and quality of outputs were claimed to have generally poor and maintenance of established development activities, e.g., soil and water conservation structures and planted trees, is inadequate (Bishop \& Hilhorst, 2010). This could be a bottleneck requiring improvement in monitoring.

\subsubsection{Contribution of using traditional fuel for climate change}

In the study area, the rural people depend on natural resources for their living. Primarily, to make food they plough land by converting the forest land in to agricultural land. Farmers depend on biomass to get energy to fulfill all their domestic energy need. During this time they cut tree to get fire wood and charcoal. Similarly, they also cut tree to construct house and to furnish their home with furniture. All these action leads for the production of carbon dioxide gases which is among the major gases of greenhouse gases and have high contribution for global climate change. Fuel wood, roots, agricultural residues and animal dung are responsible for high emissions of carbon monoxide, hydrocarbons and particulate matter (Kibria, 2015).

Of all these causes, we have a chance to mitigate our domestic contribution of carbon dioxide and the resultant climate change by renovating our energy dependence from the traditional biomass to clean, environmentally friendly, and modern renewable energy technologies systems. Renewable energy technologies provide an exceptional opportunity for mitigation of greenhouse gas emission and reducing global warming through substituting conventional energy sources (Panwar, et al., 2011). In this regard, unless we do not act immediately the costs of the climate impact will be enormous (WBU, 2009). In addition, embracing of modern energy forms are indispensable because it is capable of improving the

Page $12 / 33$ 
living standards of billions of people, particularly in developing countries, who lack access to service or whose consumption levels are far below those of people in industrialized countries (Anderson, 2000).

\subsection{Barriers to Adoption of Modern Energy Technologies}

Discussants coined many challenges as that constrained to adopt alternative energy technologies. Accordingly, rural households indicated shortage of capital or finance, access, durability and awareness to adapt alternative energy technology were the major challenges to adopt. Explicitly, (1) high initial cost, (2) lack of accounting of externalities of conventional generation, (3) lack of data and information about resources, (4) challenge of integrating renewable energy technologies into the electricity grid, (5) subsidies for conventional generation, (6) lack of storage facilities, (7) inadequate capacity to build and monitor performance of renewables, and (8) impact on agricultural land use (Sathaye, et al., 2011). Detail of discussion results narrated as follows.

\subsubsection{Shortage of capital}

Different small alternative energy technologies that can be adopted by rural households are available in the market. Finance matters adoption of the technology. Majority, $98 \%$ of respondents across the study areas reported that shortage of finance was among the key barriers to adopt small scale modern energy technologies such as solar energy for lighting, solar energy consuming radio, and hand battery (Figure 2). Although modern renewable energy technologies that can reach by government through grid system such as biofuel, geothermal, wind, solar and hydropower energy, adopting easy technologies that can be built within the household level like biogas and small solar system for basic domestic needs including for cooking and lighting is still being impossible due to financial constraint. Moreover, due to lack of finance, the rural people were even not able to use the small solar system which can only serve for lighting. Quitzow, et al., (2016) stated that for most people in Africa, energy is inaccessible, unreliable, and unaffordable. Sathaye, et al., (2011) stated that higher initial cost of renewable energy technologies compared to conventional generation options hinders their large scale adoption particularly in developing countries, where cost is a prime concern.

Due to this the rural people still rely for their fuel demand on traditional biomass and that exposed their live to diverse contest include environmental, social and health problems. Smoke from the use of fuel wood and dung for cooking contributes to acute respiratory infections (Berhanu, et al., 2017), which is worse in poor countries, particularly on women who are responsible for cooking, due to indoor pollution where houses are not equipped with separate living and cooking places (Mazzoni, et al., 2003; Geissler et al., 2013).

\subsubsection{Lack of access}

Access to technology matters the adaptation characteristics of individuals. Discussants and $97 \%$ of surveyed households across North Wollo and Wag Hemera zone stated that access to alternative energy technologies lack in their community (Figure 2). That mean, the rural household in the study area have poor access of modern alternative energy for cooking, lighting and heating purposes. Energy access 
involves access to electricity and to clean fuels and technologies for cooking, which is commonly referred to as 'clean cooking' (UNEP, 2019). Societies that depend on traditional energy activities are found at the bottom rung of the energy ladder (UNCTAD, 2010). Access is a function of availability and affordability, while for energy to be considered available to a household, the household must be within the economic connection and supply range of the energy network or supplier, affordability refers to the ability of the household to pay the up-front connection cost (or first cost) and energy usage costs (Chaurey, et al., 2004). This result in deforestation and degradation of the land and led to face serious health problem.

Therefore, improving the access of alternative energy for all residential purpose has diverse benefit. Among overwhelming benefits, improving the productivity of land and food security, as the action indirectly helps to maintain soil fertility, could be the major. In addition, modern energy reduce indoor pollution, improved educational outcomes, school children will have access to lighting to study, improved health and potential reduction in rural-urban migration (Hafner, et al., 2018). In contrast, in towns near to the rural household, there are accesses to girded electric system although they use mainly for lighting and use wood and charcoal for cooking. Access concerns need to be understood in a local context and in most countries there is an obvious difference between electrification in the urban and rural areas, this is especially true in sub-Saharan Africa and South Asian region (Brew-Hammond, 2010).

Moreover, if access to renewable modern energy is created for rural biomass dependent households that will transform the entire situation and improve socioeconomic development of the poor. Access to energy is among the key elements for the economic and social developments of Ethiopia (FDRG MoWE, 2012), and in current societies, access to energy is considered as a major factor for sustainability in both developed and developing countries (Hafner, et al., 2018). On the other hand, if the experience of using of traditional fuel continue within this pattern and action will not be taken, the practice will put back the strong desire and efforts of internationally accepted sustainable development goal to realize sustainable development in the world through switching the pattern of energy use from traditional to new renewable energy consumption. The sustainable development goal seven seeks to ensure that energy is clean, affordable, available and accessible to all and this can be achieved with renewable energy source (Owusu \& Asumadu-Sarkodie, 2016).

\subsubsection{Durability problems}

About $97 \%$ of respondents conveyed that although rural poor has been trying to adopt some small scale alternative energy technology lack of durability and robustness were the straining barriers (Figure 2). Moreover, discussants also stated durability of adaptive alternative energy technologies problem. For example, one of discussant farmers in Wolehi kebele asked a question "why technology producer are not reliable or committed to produce durable technology which can work for a long periods, e.g., solar panel? Currently, although, we didn't that much adaptive enough but technology that we rarely bought were not durable. As a result we lost our scarce money".

When rural farmers decide to adopt alternative energy sources they allocate from their poor capital which call all involved in technology innovation to produce and offer durable, easy to operate in rural context

Page 14/33 
and relatively cheap in price. This may be another opportunity to energy technology producer to get feedback on their product and to contribute their part to protect the environment and enhance sustainable development. On the other hand, households or technology users were criticized for their extra concern about the durability, safety, and convenience of a new cooking device rather they lack adequate information on the negative health outcomes associated with inefficient combustion of solid fuels which has impeded the growth of market demand for clean cooking stoves and other alternative technologies (Getachew, et al., 2018).

\subsubsection{Lack of awareness}

Awareness to different alternative energy technologies in the market and their contribution to reduce burden on their forest resources were limited among the communities. About $93 \%$ of informants stated that although there were problems with financial capacity to adopt having poor awareness about the technologies advantage affect adoption (Figure 2). Awareness on to the overwhelming impact of biomass energy utilization on soil degradation, low crop productivity, food insecurity, low animal productivity and water scarcity were poor (REN-21, 2010).

\subsection{Impact of traditional fuel consumption to sustainable livelihood}

In the move to ensure sustainable livelihood all the capabilities, assets and activities required for a means of living are needed to ensure the sustainable situation for human being to cope with and recover from stress and shocks and maintain its capabilities and assets for the future generation. The high dependence of people on the biomass energy for domestic use could affect sustainable livelihood due to natural resource depletion and limitation for alternative activities, e.g., wood and metal works, pumping ground water for irrigation, that require energy.

However, deforestation in search of additional land for farming by cutting tree was the reason for natural resource depletion but continues day to day consumption of forest resource as fuel for domestic energy were highly affected the livelihood of rural people. This implies that all the practice to secure means of living was seriously affected the productive base for both the current and future generations. The practice opposes the widely accepted concept and definition of the World Commission on Environment and Development "development that meets the needs of the present without compromising the ability of future generations to meet their own needs" (WCED, 1987; Bojo et al., 1992).

Due to deforestation, rural household income reduced and resulted in holistic poverty because it affected all the income sources of the households. Since, the only means of their livelihood, which include livestock and crop productions, were seriously affected because of scarcity to pasture, water, soil fertility, timely rainfall, and available moisture content of the area were seriously impacted. These calls to take dramatic action on the approach to shift from the traditional way of living to modern fashion with choose of energy alternatives. Because renewable technologies are considered as clean sources of energy and optimal use of these resources decreases environmental impacts, produces minimum secondary waste 
and are sustainable based on the current and future economic and social needs (Owusu \& AsumaduSarkodie, 2016). Accordingly, the shift from traditional energy use to modern renewable forms of energy source contributes not only limited to reducing impact on natural environment rather benefits the struggle to ensure food security and eradicate absolute poverty.

Therefore, the start to shift in to modern energy must began with the task to enhance the rehabilitation efforts and urge to augment an adaptive capacity of the rural household to any natural event like drought and damaging flood. Because the implication of working on rehabilitation effort and enhancing adaptive capacity means replacing the plant in place of a tree that catted to address the traditional fuel need and building the financial capacity to adopt modern new renewable energy technology respectively. Sawin, et al., (2016) noted that societies around the world are on the verge of a profound and urgently necessary transformation in the way they produce and use energy. UN, (2011) because they understood that even though it's convenient to use coal, oil, and natural gas for meeting their energy needs, they have a limited supply of these fuels on the Earth and eventually they will run out since the present patterns of use of those nonrenewable sources of energy are much more rapidly than they are being created.

Hence, huge investments are needed in additional and replacement capacity for producing, converting, transporting and distributing energy in developing countries to meet the current and future needs of renewable energy option (OECD, 2007). Besides, identified three inter-linked objectives that are necessary for long-term sustainable development in the world in relation to access to energy by the Sustainable Energy for All Initiative also confirms the importance of taking urgent action to ensure sustainable development and eradicate poverty. These includes ensure universal access to modern energy services; double the rate of improvement in energy efficiency; and double the share of renewable energy in the global energy mix (Vezzoli, et al., 2018).

\section{Result And Discussion}

\subsection{Livelihood strategies of the community}

From focus group discussion and field observation, it was learned that, in the study area, crop-livestock mixed farming is the main means of living Crop production takes the highest land share because of land scarcity and economic capacity to own animals. Even though crop production was more practiced, it does not satisfy their annual food demand and thus, they rely on external food aid (Assefa, et al., Submitted). Teff, sorghum, and maize were the most major crop types, and cattle, goat, sheep, donkey, and poultry are commonly reared livestock.

\subsection{Domestic energy sources of the rural household}

From the focus group discussion and observations in the area, it was evident that biomass is the highest source of energy on which the entire rural households rely. All the respondents (100\%) reported that fire wood is used as a fuel for cooking, lighting and heating purposes. Although the extent is very low, they support their energy need with animal dung (85.49\%) and crop residue (83.55\%) for cooking, and some 
also use kerosene (46.09\%) and only $4.09 \%$ use small scale alternative energy sources like solar for lighting. Besides, very few, $4.57 \%$ of the respondents indicated that they use charcoal for heating and rarely use for coffee ceremony and majorities prepare and sell it to the urban residents (Table 1). Cooking was done primarily by firewood, and followed by animal dung and crop residues. Crop residue was used especially in the dry season at the time of harvesting period. Modi, (2004) found that poor individuals without access to modern energy source rely on traditional energy such as fuel wood and charcoal, which lead to environmental degradation such as desertification and soil erosion. In Ethiopia, studies showed that, the share of traditional biomass fuel (i.e., in the form of wood, charcoal and dung) accounts $~ 90 \%$ of total primary energy use of the household (Mekonnen and Kohlin, 2009), and about $84 \%$ and $99 \%$ of urban and rural households, respectively, rely on biomass as their primary fuel for cooking (Gurmessa, 2010). The practice was also common in many Sub-Saharan Africa, example, in Zambia where fuel wood is used for cooking and heating by $97 \%$ of rural and $85 \%$ of urban households (Central Statistics Office, 2005), and generally it is the major source of energy and contributing to over $70 \%$ of the total national energy budget (GRZ, 2007).

Table 1: Domestic energy sources on which rural households relied

\begin{tabular}{|llll|}
\hline Domestic energy sources & $\begin{array}{l}\text { North Wollo } \\
(\mathbf{n = 2 1 5})\end{array}$ & $\begin{array}{l}\text { Wag Hemera } \\
(\mathbf{n = 1 8 3})\end{array}$ & $\begin{array}{l}\text { Average } \\
(\mathbf{n}=\mathbf{3 9 8})\end{array}$ \\
\cline { 2 - 4 } & $\%$ & $\%$ & $\%$ \\
\hline Fire wood & 100 & 100 & $\mathbf{1 0 0 . 0 0}$ \\
\hline Dung cake & 84.19 & 86.79 & $\mathbf{8 5 . 4 9}$ \\
\hline Crop residue & 85.12 & 81.97 & $\mathbf{8 3 . 5 5}$ \\
\hline Charcoal & 3.09 & 6.05 & 4.57 \\
\hline Kerosene & 47.91 & 44.26 & 46.09 \\
\hline $\begin{array}{l}\text { Small scale of alternative energy technology } \\
\text { (Solar or electricity) }\end{array}$ & 3.26 & 4.92 & 4.09 \\
\hline
\end{tabular}

Sources: Own survey

The high dependence of rural households on traditional fuel was mainly associated to the economic development level of the country and settlement pattern of the community. Despite the technology advancement in alternative energy sources, the practice of using it was not considerable in the area. Moreover, FGD discussants said that the use of forest as main source of domestic energy has attained difficult state. On one hand, forest/woodland has been declining progressively compared to the situation in past (30-40 years ago). Musa and Azare (2016) indicated that in the past, the source of fuel wood was simple, and the environmental impacts arising from its exploitation were minimal due to low human 
population, however, as a result of population increase, dependence on wood as a source of fuel started showing signs of inadequacy.

On the other hand, the discussants explained that cutting tree for fire wood adversely affect land productivity and food security due to solemn degradation since tree and their emendate environment are the main sources of their livelihood. Even due to the previous unwise act, the community has been observing severe drought and loss of their livings including damage on their land. Replanting and growing tree will not be as easy as utilizing tree as the semi-arid environmental situation challenge growth. Dawit (2010) also noted that the huge amount of wood consumption, especially in the rural areas, is a catastrophic to the environment as tree plantation to replace them is not so common. The resulted deforestation that has been going on for many decades is also a cause to biodiversity loss and soil erosion which in turn affects the balance of the ecosystem. Generally, the upturning cumulative impacts of using traditional biomass as energy source on the livelihood and both rural and urban human wellbeing appear as the main insistent factor to switch from traditional energy source to modern sources but net yet.

\subsection{Effects of rural household dependence on biomass for fuel on forest resources}

The impacts of historical droughts, domestic consumption of tree, population growth, natural and accelerated aridity of the land, and the impact of current climate change were noted as the key reasons for the existing poor coverage of forest in the area. Discussants said that the communities were severely maltreated by droughts occurred in 1955, 1965, 1975, 1985, 1995, 2005 and 2015. Of these, although all the mentioned had caused comparable and continued impact on the community, the 1985 drought was caused the most severe impact on the human lives and forest resource. Dryness of trees and consequent depletion of natural resource including the fertile topsoil and the consequent poverty were among the most mentioned.

All the respondents (100\%) and discussants stated human contribution for the clearance of tree outweigh than the impact of drought (Figure 1). Although cutting trees for fire wood, house construction and other forest product like timber causes deforestation, conversion of forest land into cultivated land is also important cause of deforestation (FAO, 2016), which increase erosion, land degradation, biodiversity loss, food insecurity and poverty (FAO, 2017). Understanding the multiple side effects of deforestation on human life including local energy supply, there is growing interest to rehabilitate the area through massive plantation by government and non-government organizations. Despite natural and accelerated aridity that hinders the growth of forest biomass, dependence for fuel appeared as serious problem for an effective rehabilitation in the study area. Globally, enduring dependence of energy on fire wood for cooking, heating and lighting was added additional burden on land rehabilitation and poverty reduction efforts. FAO, (2017) stated that limited availability of, and access to fire wood fuel could exacerbate hunger and poverty by challenging the primary energy source for various purposes including cooking.

The impact of energy problem moves from environmental and economic to social, example, through imposing women to move long distant to collect fire wood. Mazzoni, et al., (2003) stated that traditional 
fuel use has disproportionate effects on women, and contributes further to the social inequalities that are, for instance, caused by an uneven distribution of fuel-collection, cooking, and childcare responsibilities between men and women within the household. Of all these, the worst situation was the lack of no progress to switch from relying on traditional energy, which reached to no capacity to offer needed service, to alternative energy source. Because, in the nearby area, there were no forestlands from which the people could access fire wood easily though less recommended. Thus, community more rely on the animal dung and crop residue, which have still its own effect on the efforts to ensure food security.

\subsubsection{Effects of biomass fuel utilization on agricultural production}

Cutting tree for domestic energy source such as for fire wood and charcoal were among the key causes for the continued removal of forest resource and resultant low soil fertility, $100 \%$ of the respondents reported (Figure 1). Demands of fuel increase due to ever growing population that relies on biomass for fuel. In urban areas, where alternative energy such as electricity is available, due to cultural background and cost, Ethiopians prefer charcoal for cooking and heating. This adds to deforestation and land degradation through soil erosion and wind. In the study area, due to severe shortage of wood, animal dung has been used as energy sources for cooking, which should have been utilized for fertilizing cropland. Studies showed that cattle dung contains essential nutrients such as potassium, phosphorus and nitrogen and organic carbon, which have significant role on soil fertility (Nyamangara et al., 2001; Lakasi et al., 2003; Negasa et al., 2017). Thus, utilization of cattle dung for energy could adversely affect crop production.

In the study area, farmers use crop residue, mainly residue of maize and sorghum for fuel, and residue of crops such as teff is used for feeding livestock. From nutrient recycling and maintaining soil quality and reducing erosion perspectives, keeping residue on cropland is important (Turmel et al., 2014). Thus, removing residue, e.g., for fuel could affect cropland productivity and food security. As a result the farmers live in impoverished situation due to presence of both acute and transitory poverty. Because, the effects of degradation on land productivity; agriculture and livestock production had a negative effect on livelihoods of the community (Habtamu, et al., 2015). Biomass of the study site was highly impacted by repeatedly occurred severe drought, traditional farming practice and energy utilization pattern. The biomass production of the area is not sufficient to provide enough feed for livestock.

Discussants explained that land is being infertile and they could not be able to cover the consumption need of the household. About $97 \%$ of the surveyed households relate low productivity with loss of tree cover, which has several environmental benefit including erosion reduction and climate control, as they expressed (Figure 1). Deforestation causes drought and flooding, among others, leading to a decline in agricultural yields and food security (Berhanu, et al., 2017).

Utilization of biomass for energy could have multiple effects on livestock production. Accordingly, about $95 \%$ of surveyed respondents reported that the present energy need for fire wood has been provoking the challenges of livestock production and productivity in many dimensions such as loss of grass; increase the prevalence of disease, and access to water (Figure 1). Land degradation due to forest could reduce 
availability of forage and water. That means, farmers were facing stern challenge to found pasture and water for their animals. While challenge for grass was due to couple of problems such as land degradation and sacristy of grassing land, accessibility of water especially during the dry season was mainly due to land degradation that caused by clearing tree or due to the biomass was destroyed. The perceived climate change due to deforestation and land degradation could be less suitable for livestock. Example, temperature affects most of the critical factors of livestock production, such as water availability, animal production and reproduction, and animal health (mostly through heat stress) (IPCC, 2019). This created favorable conditions for the occurrence of animal disease and affected the health of livestock. Rojas-Downing, et al., (2017) livestock diseases are mostly affected by increases in temperature and precipitation variation. Due to various infectious animal diseases caused by climate change, farmers lost their livestock and pressurized to have only few, affecting their livelihood.

Water availability of the area is low, particularly in dry season, which is associated to increased surface runoff in rainy season resulting from land degradation due to, partly, removing forest and other biomass for fuel. In this regard, about $87 \%$ of informants reported access to water was the pressing challenges in the area, which was due to primary dependence of the rural dwellers for wood on biomass (Figure 1). FAO (2015) stated that forests play a crucial role in the partitioning of water into surface flow, subsurface flow, and evapotranspiration. In contrast, the removals of forest and other biomass strongly impair the hydrological functioning of the environment (Todd-Brown, et al., 2013). Thus, discussants explained that due to land degradation ponds and water points were progressively dried up in the area. Reis-Pereira, et

al., (2014) and Chakravarty, et al., (2012) pointed out that any change in the original land use can result in significant alterations of the water balance components of a watershed.

The observed scarcity of water in the area affected their live in various aspects: farmers were pressed to travel distant area in search of water for their livestock and domestic consumption especially by women. It added double burden on the farmers' livelihood through sharing their precious time and affecting their health. Water shortage affects crop production and livestock.

\subsubsection{Implication of biomass energy utilization on household food insecurity}

In the study area, there has been chronic food insecurity for more than three decades (Assefa et al., submitted). Focus group discussants and $98 \%$ of surveyed households indicated that land degradation partly due to utilization of biomass (fuel wood, charcoal, crop residue and animal dung) for energy contributed to the existing nasty food insecurity. As a result, farmers' ability to feed own household from self-production was very low, which might be not more than six months per year. The remaining months would be covered by donor based food aid, in the area, which was the long-existed trend In particular, following the Great Ethiopian Famine of 1984-1985, for example, more than 5 million people, majority are from northern region, have received food aid in the country on annual basis, indicating a situation of chronic food insecurity (Aschale, 2012). The land degradation, partly, due to back warded biomass energy utilization contributes for food insecurity. 
The constant supply of food aid for the poor farmers with the aim of filling the yearly food gap had been passed two periods. Before 2005 the support of food was offered with the central aim of humanitarian act, since that time the support was shaped to developmental forms. On the other word, the previous cater of food for the needy people in the area was primarily initiated by natural event mainly drought but the revised forms of support of food aid was aimed to reduce food insecurity through the developmental activities like watershed management practices through the model of food-for-work. In the revised approach of food aid the eligible household, 'poor-of the-poor, could receive aid up on participating on developmental activities such as watershed management, which supposed to restore degraded land and perhaps improve the biomass energy supply. The food-for-work approach received great attention due to growing government, NGOs and development partners' interest to restore degraded landscape.

Environmental rehabilitation as a strategy for delivering food relief seemed a good approach of using relief to development, but the productivity and quality of outputs were claimed to have generally poor and maintenance of established development activities, e.g., soil and water conservation structures and planted trees, is inadequate (Bishop \& Hilhorst, 2010). This could be a bottleneck requiring improvement in monitoring.

\subsubsection{Contribution of using traditional fuel for climate change}

In the study area, the rural people depend on natural resources for their living. Primarily, to make food they plough land by converting the forest land in to agricultural land. Farmers depend on biomass to get energy to fulfill all their domestic energy need. During this time they cut tree to get fire wood and charcoal. Similarly, they also cut tree to construct house and to furnish their home with furniture. All these action leads for the production of carbon dioxide gases which is among the major gases of greenhouse gases and have high contribution for global climate change. Fuel wood, roots, agricultural residues and animal dung are responsible for high emissions of carbon monoxide, hydrocarbons and particulate matter (Kibria, 2015).

Of all these causes, we have a chance to mitigate our domestic contribution of carbon dioxide and the resultant climate change by renovating our energy dependence from the traditional biomass to clean, environmentally friendly, and modern renewable energy technologies systems. Renewable energy technologies provide an exceptional opportunity for mitigation of greenhouse gas emission and reducing global warming through substituting conventional energy sources (Panwar, et al., 2011). In this regard, unless we do not act immediately the costs of the climate impact will be enormous (WBU, 2009). In addition, embracing of modern energy forms are indispensable because it is capable of improving the living standards of billions of people, particularly in developing countries, who lack access to service or whose consumption levels are far below those of people in industrialized countries (Anderson, 2000).

\subsection{Barriers to Adoption of Modern Energy Technologies}

Discussants coined many challenges as that constrained to adopt alternative energy technologies. Accordingly, rural households indicated shortage of capital or finance, access, durability and awareness 
to adapt alternative energy technology were the major challenges to adopt. Explicitly, (1) high initial cost, (2) lack of accounting of externalities of conventional generation, (3) lack of data and information about resources, (4) challenge of integrating renewable energy technologies into the electricity grid, (5) subsidies for conventional generation, (6) lack of storage facilities, (7) inadequate capacity to build and monitor performance of renewables, and (8) impact on agricultural land use (Sathaye, et al., 2011). Detail of discussion results narrated as follows.

\subsubsection{Shortage of capital}

Different small alternative energy technologies that can be adopted by rural households are available in the market. Finance matters adoption of the technology. Majority, $98 \%$ of respondents across the study areas reported that shortage of finance was among the key barriers to adopt small scale modern energy technologies such as solar energy for lighting, solar energy consuming radio, and hand battery (Figure 2). Although modern renewable energy technologies that can reach by government through grid system such as biofuel, geothermal, wind, solar and hydropower energy, adopting easy technologies that can be built within the household level like biogas and small solar system for basic domestic needs including for cooking and lighting is still being impossible due to financial constraint. Moreover, due to lack of finance, the rural people were even not able to use the small solar system which can only serve for lighting. Quitzow, et al., (2016) stated that for most people in Africa, energy is inaccessible, unreliable, and unaffordable. Sathaye, et al., (2011) stated that higher initial cost of renewable energy technologies compared to conventional generation options hinders their large scale adoption particularly in developing countries, where cost is a prime concern.

Due to this the rural people still rely for their fuel demand on traditional biomass and that exposed their live to diverse contest include environmental, social and health problems. Smoke from the use of fuel wood and dung for cooking contributes to acute respiratory infections (Berhanu, et al., 2017), which is worse in poor countries, particularly on women who are responsible for cooking, due to indoor pollution where houses are not equipped with separate living and cooking places (Mazzoni, et al., 2003; Geissler et al., 2013).

\subsubsection{Lack of access}

Access to technology matters the adaptation characteristics of individuals. Discussants and $97 \%$ of surveyed households across North Wollo and Wag Hemera zone stated that access to alternative energy technologies lack in their community (Figure 2). That mean, the rural household in the study area have poor access of modern alternative energy for cooking, lighting and heating purposes. Energy access involves access to electricity and to clean fuels and technologies for cooking, which is commonly referred to as 'clean cooking' (UNEP, 2019). Societies that depend on traditional energy activities are found at the bottom rung of the energy ladder (UNCTAD, 2010). Access is a function of availability and affordability, while for energy to be considered available to a household, the household must be within the economic connection and supply range of the energy network or supplier, affordability refers to the ability of the 
household to pay the up-front connection cost (or first cost) and energy usage costs (Chaurey, et al., 2004). This result in deforestation and degradation of the land and led to face serious health problem.

Therefore, improving the access of alternative energy for all residential purpose has diverse benefit. Among overwhelming benefits, improving the productivity of land and food security, as the action indirectly helps to maintain soil fertility, could be the major. In addition, modern energy reduce indoor pollution, improved educational outcomes, school children will have access to lighting to study, improved health and potential reduction in rural-urban migration (Hafner, et al., 2018). In contrast, in towns near to the rural household, there are accesses to girded electric system although they use mainly for lighting and use wood and charcoal for cooking. Access concerns need to be understood in a local context and in most countries there is an obvious difference between electrification in the urban and rural areas, this is especially true in sub-Saharan Africa and South Asian region (Brew-Hammond, 2010).

Moreover, if access to renewable modern energy is created for rural biomass dependent households that will transform the entire situation and improve socioeconomic development of the poor. Access to energy is among the key elements for the economic and social developments of Ethiopia (FDRG MoWE, 2012), and in current societies, access to energy is considered as a major factor for sustainability in both developed and developing countries (Hafner, et al., 2018). On the other hand, if the experience of using of traditional fuel continue within this pattern and action will not be taken, the practice will put back the strong desire and efforts of internationally accepted sustainable development goal to realize sustainable development in the world through switching the pattern of energy use from traditional to new renewable energy consumption. The sustainable development goal seven seeks to ensure that energy is clean, affordable, available and accessible to all and this can be achieved with renewable energy source (Owusu \& Asumadu-Sarkodie, 2016).

\subsubsection{Durability problems}

About $97 \%$ of respondents conveyed that although rural poor has been trying to adopt some small scale alternative energy technology lack of durability and robustness were the straining barriers (Figure 2). Moreover, discussants also stated durability of adaptive alternative energy technologies problem. For example, one of discussant farmers in Wolehi kebele asked a question "why technology producer are not reliable or committed to produce durable technology which can work for a long periods, e.g., solar panel? Currently, although, we didn't that much adaptive enough but technology that we rarely bought were not durable. As a result we lost our scarce money".

When rural farmers decide to adopt alternative energy sources they allocate from their poor capital which call all involved in technology innovation to produce and offer durable, easy to operate in rural context and relatively cheap in price. This may be another opportunity to energy technology producer to get feedback on their product and to contribute their part to protect the environment and enhance sustainable development. On the other hand, households or technology users were criticized for their extra concern about the durability, safety, and convenience of a new cooking device rather they lack adequate information on the negative health outcomes associated with inefficient combustion of solid fuels which 
has impeded the growth of market demand for clean cooking stoves and other alternative technologies (Getachew, et al., 2018).

\subsubsection{Lack of awareness}

Awareness to different alternative energy technologies in the market and their contribution to reduce burden on their forest resources were limited among the communities. About $93 \%$ of informants stated that although there were problems with financial capacity to adopt having poor awareness about the technologies advantage affect adoption (Figure 2). Awareness on to the overwhelming impact of biomass energy utilization on soil degradation, low crop productivity, food insecurity, low animal productivity and water scarcity were poor (REN-21, 2010).

\subsection{Impact of traditional fuel consumption to sustainable livelihood}

In the move to ensure sustainable livelihood all the capabilities, assets and activities required for a means of living are needed to ensure the sustainable situation for human being to cope with and recover from stress and shocks and maintain its capabilities and assets for the future generation. The high dependence of people on the biomass energy for domestic use could affect sustainable livelihood due to natural resource depletion and limitation for alternative activities, e.g., wood and metal works, pumping ground water for irrigation, that require energy.

However, deforestation in search of additional land for farming by cutting tree was the reason for natural resource depletion but continues day to day consumption of forest resource as fuel for domestic energy were highly affected the livelihood of rural people. This implies that all the practice to secure means of living was seriously affected the productive base for both the current and future generations. The practice opposes the widely accepted concept and definition of the World Commission on Environment and Development "development that meets the needs of the present without compromising the ability of future generations to meet their own needs" (WCED, 1987; Bojo et al., 1992).

Due to deforestation, rural household income reduced and resulted in holistic poverty because it affected all the income sources of the households. Since, the only means of their livelihood, which include livestock and crop productions, were seriously affected because of scarcity to pasture, water, soil fertility, timely rainfall, and available moisture content of the area were seriously impacted. These calls to take dramatic action on the approach to shift from the traditional way of living to modern fashion with choose of energy alternatives. Because renewable technologies are considered as clean sources of energy and optimal use of these resources decreases environmental impacts, produces minimum secondary waste and are sustainable based on the current and future economic and social needs (Owusu \& AsumaduSarkodie, 2016). Accordingly, the shift from traditional energy use to modern renewable forms of energy source contributes not only limited to reducing impact on natural environment rather benefits the struggle to ensure food security and eradicate absolute poverty. 
Therefore, the start to shift in to modern energy must began with the task to enhance the rehabilitation efforts and urge to augment an adaptive capacity of the rural household to any natural event like drought and damaging flood. Because the implication of working on rehabilitation effort and enhancing adaptive capacity means replacing the plant in place of a tree that catted to address the traditional fuel need and building the financial capacity to adopt modern new renewable energy technology respectively. Sawin, et al., (2016) noted that societies around the world are on the verge of a profound and urgently necessary transformation in the way they produce and use energy. UN, (2011) because they understood that even though it's convenient to use coal, oil, and natural gas for meeting their energy needs, they have a limited supply of these fuels on the Earth and eventually they will run out since the present patterns of use of those nonrenewable sources of energy are much more rapidly than they are being created.

Hence, huge investments are needed in additional and replacement capacity for producing, converting, transporting and distributing energy in developing countries to meet the current and future needs of renewable energy option (OECD, 2007). Besides, identified three inter-linked objectives that are necessary for long-term sustainable development in the world in relation to access to energy by the Sustainable Energy for All Initiative also confirms the importance of taking urgent action to ensure sustainable development and eradicate poverty. These includes ensure universal access to modern energy services; double the rate of improvement in energy efficiency; and double the share of renewable energy in the global energy mix (Vezzoli, et al., 2018).

\section{Conclusion}

Currently, about $80 \%$ of Ethiopians live in the rural area where traditional biomass is the main sources of domestic energy and access to gird electric system is yet uncommon. The traditional energy sources include firewood, charcoal, crop residues and animal dung. The use of that biomass energy led to many negative impacts, which ranges from environmental degradation that resulted on food insecurity to the health effects of combustion smokes and fuel handling.

Although the negative impact resulted from it cases important challenges to the efforts of society development, its contribution to deep rooted food insecurity is very serious in the northern highland and it demands an urgent action to solve the problem. As part of the solution to the problems there are many alternative energy sources that could be promoted in the international level but the opportunity to use them were not being possible to the rural households in the study area. Shortage of capital or finance, access, durability and awareness were existed as main barriers to adapt modern energy sources.

This calls technology developers, bilateral organizations and NGOs to promote alternative modern energy technologies that are easy accessible both in terms of availability and affordability, and operable by rural people. Because, its promotion with all the necessary requirements has many implications that ranges from reducing the consumption of biomass fuel to the reduction of food insecurity problem and climate change including the positive contribution to the attainment of sustainable development goals. 


\section{Declarations}

\section{Ethics approval and consent to participate}

Ethical clearance was obtained from Research Ethical Review Committee (RERC) of Ambo University, Director of Research and Community Services, and permission and supporting letter from Amhara zone administration with facilitation of ORDA (Organization for Rehabilitation and Development in Amhara) working for Amhara before data collection. Verbal informed consent from each participant was obtained during data collection. The respondents were given the right to refuse to take part in the study as well as to withdraw at any time during the study. All participants, farmers and experts were assured of confidentiality.

\section{Consent for publish}

The authors obtained permission from all participants in Amhara zone to publish their data.

\section{Declaration}

We declare that there is no any known conflict of interest on this research output.

\section{Availability of data and materials}

First author will provide data on reasonable request.

\section{Competing interests}

The authors declare that they have no competing interests.

\section{Funding}

The research fund for this study was obtained from United States of America for International Development (USAID) under the Productive Safety Net Programme (PSNP).

\section{Authors' contributions}

Daniel Assefa designed the data collection tools, undertook fieldwork and most of the analysis, and developed the manuscript. Dr. Kebede Wolka \& Dr. Teshale Woldeamanuel contributed in formatting the manuscript, subsidized through reading and edited the manuscript. Accordingly, all the authors read and approved the final manuscript.

\section{Acknowledgements}

The authors are grateful for the financial support from the United States of America for International Development (USAID). They are also grateful to the World Vision Ethiopia and International Livestock Research Institute (ILRI) for founding the fund from USAID and for contributing technical support during 
the research work respectively. Authors would like to acknowledge Ambo University for hosting the project and coordination during the life of the research project work. Researchers also would like to send special thanks to North Wollo and Wag Hemera zone poor aid dependent farmers, development agents and experts for providing relevant data and hospitable cooperation during field work.

\section{References}

1. African Development Bank (2017) The new deal on energy for Africa. A transformative partnership to light up and power Africa by 2025. Update of implementation. https://www.afdb.org/fileadm in/uploads/afdb/Documents/Generic-Documents/Brochure_New_Deal_2_red.pdf. Accessed 13 Dec 2017

2. Almalki S (2016) Integrating Quantitative and Qualitative Data in Mixed Methods ResearchChallenges and Benefits. Journal of Education and Learning; Vol. 5, No. 3; 2016

3. Amhara Region Biro of Finance \& Economy Development (BoFED) (2013) Statstical abstrat 2. Bahirdar.

4. Anderson D (2000) Energy and economic prosperity. In: Goldemberg J (ed) World energy assessment: Energy and the challenges of sustainability. United Nations Development Programme, New York, pp 393-414

5. Aschale Dagnachew Siyoum (2012) Broken Promises:Food Security Interventions and Rural Livelihoods in Ethiopia

6. Ávila P, Oliver MJ, Gallego P, González-García A, Rodríguez-Puras JM, Cambronero E, Ruiz-Cantador J, Campos A, Peinado R, Prieto R, Sarnago F, Fernández-Avilés F (2017) Natural History and Clinical Predictors of Atrial Tachycardia in Adults With Congenital Heart Disease. Circ Arrhythm Electrophysiol. 2017;10:e005396. DOI: 10.1161/CIRCEP.117.005396

7. Barnes FD, Golumbeanu R, Diaw I (2016) Beyond Electricity Access: Output-Based Aid and Rural Electrification in Ethiopia. Energy for Development, Washington, DC; World Bank, November 2016

8. Birhanu Iticha M, Kibebew Kibret (2016) Impact of deforestation and subsequent cultivation on soil fertility in Komto, Western Ethiopia. Journal of Soil Science and Environmental Management

9. Bishop C, Hilhorst D (2010) From food aid to food security: the case of the Safety Net policy in Ethiopia. J. of Modern African Studies, 48, 2 (2010), pp. 181-202. $f$ Cambridge University Press 2010 doi:10.1017/S0022278X10000248

10. BMZ (2014) Sustainable Energy for Development. Germen Development Cooperation in the Energy Sector

11. Bojo J et al (1992) Environment and Development: An Economic Approach. Kluwer Academic Publishers

12. Brew-Hammond A (2010) Energy access in Africa: Challenges ahead. Energy Policy 38:2291-2301. http://dx.doi.org/10.1016/j.enpol.2009.12.016 
13. Bruijnzeel LA, Bonell M (2005) Tropical montane cloud forest: a unique hydrological case. In: Bonell M, Bruijnzeel LA (eds) Forests, Water and People in the Humid Tropics. Cambridge University Press, Cambridge, UK, pp 462-483

14. Central Statistical Agency (CSA) (2013) Population Projection of Ethiopia for All Regions at Woreda Level from 2014 - 2017. Addis Ababa. Ethiopia

15. Chakravarty SK, Ghosh CP, Suresh AN, Dey, Shukla G (2012) Deforestation: Causes, Effects and Control Strategies, Global Perspectives on Sustainable Forest Management, Dr. Dr. Clement A. Okia (Ed.), ISBN: 978-953-51-0569-5, InTech, Available from:

http://www.intechopen.com/books/globalperspectives- on-sustainable-forestmanagement/deforestation-causes-effects-and-control-strategies

16. Chaurey A, Ranganathana M, Mohanty P (2004) Electricity access for geographically disadvantaged rural communities - technology and policy insights. Energy Policy, No.32.

17. Cherni AJ (2008) Renewable Energy for Rural Sustainability in Developing Countries. See discussions, stats, and author profiles for this publication at: https://www.researchgate.net/publication/249747717

18. Creswell JW, Clark VLP (2007) Designing and conducting mixed methods research. Sage, Thousand Oaks, CA

19. Daniel A, Kebede Wolka (2021) Fate of Food Aid Dependent Farmers in the Face of Puzzling Climate Variability in the Ethiopia Highland. Implication for Policy Design. (Under review article)

20. Dawit Hailu Mazengia (2010) Ethiopian Energy Systems: Potentials, Opportunities and Sustainable Utilization. Examensarbete i Hållbar Utveckling 7. INSTITUTIONEN FÖR GEOVETENSKAPER

21. Devereux S (2000) Food Insecurity in Ethiopia, A discussion paper for DFID, Sussex, UK: Institute of Development Studies (IDS)

22. Dey I (1993) Qualitative data analysis: A user-friendly guide for social scientists

23. Eshetu Gebre G, Alemu Lelago (2017) Berhan \&. Application of Remote Sensing and GIS to Characterize Agricultural Drought Conditions in North Wollo Zone, Amhara Regional State, Ethiopia. Journal of Natural Sciences Research. www.iiste.org

24. Ethiopian Electric Power (EEP) (2016) Transmission Upgrading \& Reinforcement Project Coordination Office, Ethiopian Electric Power. EEP) Addis Ababa, Ethiopia, p 201

25. FAO (Food \& Agriculture Organization) (2016) State of the World's Forests 2016 - Forests and agriculture: land use challenges and opportunities. Rome

26. FAO (Food \& Agriculture Organization) (2017) Social protection for building the resilience of forestdependent people. Evidence, linkages, practices and potential applications. United Nations University; With assistance from Omar Rodríguez, United Nations University

27. FAO, IFAD, UNICEF, WFP and WHO (2019) The State of Food Security and Nutrition in the World 2019. Safeguarding against economic slowdowns and downturns. Rome, FAO. Licence: CC BY-NC-SA 3.0 IGO 
28. FDRG-MoWE (Federal Democratic Republic of Ethiopia Ministry of Water and Energy) (2012) Federal Democratic Republic of Ethiopia Ministry of Water and Energy. Scaling - Up Renewable Energy Program; Ethiopia Investment Plan. (Draft Final)

29. Geissler S, Hagauer D, Horst A, Krause M, Sutcliffe P (2013) Biomass energy strategy Ethiopia. Eschborn: European Union Energy Initiative Partnership Dialogue Facility; 2013 (http:// www.eueipdf.org/sites/default/files/ field_publication_file/Ethiopia_Biomass_ Energy_Strategy_and_Action_Plan_Final_2014_02_06.pdf, accessed 3 June 2018)

30. Gray L, Boyle A, Francks E, Yu V (2018) The power of small-scale solar: gender, energy poverty, and entrepreneurship in Tanzania. Development in Practice, [online] pp.1-14. Available at: https://doi.org/10.1080/09614524.2018.1526257 [Accessed 23 Oct. 2018]

31. GRZ (2007) National energy policy. Ministry of Energy and Water Development, Lusaka

32. Gurmessa F (2010) Floristic Composition and Structural Analysis of Komto Afromontane Rainforest, East Wollega Zone of Oromia Region, West Ethiopia (Doctoral dissertation, MSc. Thesis, Addis Ababa University, Addis Ababa)

33. Habtamu Terefe C, Fininsa SS, KindieTesfaye (2015) Effect of Integrated Climate Change Resilient Cultural Practices on Productivity of Faba Bean (Vicia faba L.) under Rain-fed Conditions in Hararghe Highlands, Ethiopia. East African Journal of Sciences (2015) Volume 9 (2) 105-120

34. Hafner MH, Tagliapietra S, de Strasser L (2018) Energy in Africa. Challenges and Opportunities. SPRINGER BRIEFS IN ENERGY

35. Hancock B, Ockleford E, Windridge K (2009) An Introduction to Qualitative Research. National Institute for Health Research (NIHR). The NIHR RDS EM/YH

36. IEA (International Energy Agency) (2014) Africa energy outlook: A focus on energy prospects in subSaharan Africa. Paris

37. International Renewable Energy Agency (2015) Africa 2030:roadmap for a renewable energy future

38. IPCC (Intergovernmental Panel on Climate Change) (2019) Food Security. In: Climate Change and Land: an IPCC special report on climate change, desertification, land degradation, sustainable land management, food security, and greenhouse gas fluxes in terrestrial ecosystems. Food security

39. Karekezi S, Kithyoma W (2003) Renewable energy in Africa: Prospects and limits. The Workshop for African Energy Experts on Operationalizing the NEPAD Energy Initiative, Dakar, Senegal. Retrieved November 28, 2006, from http://www.un.org/esa/ sustdev/sdissues/energy/op/nepadreport.pdf

40. Kibria G (2015) Sustainable Energy for Rural Development in Bangladesh- Economic, Social and Environmental Benefits of Renewable Energy. 7p. DOI: 10.13140/RG.2.1.1669.0401

41. Lekasi JK, Tanner JC, Kimani SK, Harris PJC (2003) Cattle manure quality in Maragua District, Central Kenya: effect of management practices and development of simple methods of assessment. Agric Ecosyst Environ 94(3):289-298

42. Malina AM, Nørreklit OSH, Selto HF (2010) Lessons Learned: Advantages and Disadvantages of Mixed Method Research. Available at: https://www.researchgate.net/publication/228312666 
43. Mazzoni G, Memon A (2003) Imagination can create false autobiographical memories. Psychol Sci 14:186-188

44. Meikle S, Bannister A (2003) Energy, Poverty and Sustainable Urban Livelihoods. Working Paper No. 126 ISSN 1474-3280

45. Mekonnen A, Kohlin G (2009) Determinants of household fuel choice in major cities in Ethiopia

46. Modi V, McDade S, Lallement D, Saghir J (2005) Energy Services for the Millennium Development Goals. Energy Sector Management Assistance Programme, United Nations Development Programme, UN Millennium Project and World Bank, New York, NY, USA

47. Mohajan KH (2018) Qualitative Research Methodology in Social Sciences and Related Subjects. Journal of Economic Development, Environment and People, Vol-7, Issue 01, 2018, pp. 23-48

48. Myers MD (2009) Qualitative research in business and management. Sage, London, UK

49. Negasa T, Ketema H, Legesse A, Sisay M, Temesgen H (2017) Variation in soil properties under different land use types managed by smallholder farmers along the toposequence in southern Ethiopia. Geoderma 290:40-50

50. Nyamangara J, Gotosa J, Mpofu SE (2001) Cattle manure effects on structural stability and water retention capacity of a granitic sandy soil in Zimbabwe. Soil Tillage Res 62:157-162

51. O'Connor H, Gibson N (2003) A Step-by-Step Guite to Qualitative Data Analysis. Originally prepared as part of the Community Associates' training Workshop (Social and Cultural Factors in the Prevention and Treatment of Tuberculosis inHigh Risk Populations in Alberta)

52. OECD (ORGANISATION FOR ECONOMIC CO-OPERATION AND DEVELOPMENT) (2007) OECD Contribution to the United Nations Commission on Sustainable Development 15. ENERGY FOR SUSTAINABLE DEVELOPMENT

53. Olagunju ET (2015) Impacts of Human-induced Deforestation, Forest Degradation and Fragmentation on Food Security. See discussions, stats, and author profiles for this publication at: https://www.researchgate.net/publication/336232078

54. Owusu AP, Asumadu-Sarkodie S (2016) A review of renewable energy sources, sustainability issues and climate change mitigation. Civil \& Environmental Engineering Review Article. http://dx.doi.org/10.1080/23311916.2016.1167990

55. Panwar N, Kaushik S, Kothari S (2011) Role of renewable energy sources in environmental protection: A review. Renew Sustain Energy Rev 15:1513-1524.

http://dx.doi.org/10.1016/j.rser.2010.11.037

56. Polkinghorne DE (2005) Language and Meaning: Data Collection in Qualitative Research. J Couns Psychol 52:137-145

57. Quitzow R, Roehrkasten S, Jacobs D, Bayer B, Jamea E, Waweru Y (2016) The future of Africa's energy supply. Institute for Advanced Sustainability Studies Potsdam, Potsdam, Germany

58. REN-21 (2010) Renewables 2010: Global Status Report. Renewable Energy Policy Network for the 21st Century Secretariat, Paris, France, $80 \mathrm{pp}$ 
59. Rojas-Downing MM, Nejadhashemi AP, Harrigan T, Woznicki SA (2017) Climate change and livestock: impacts, adaptation, and mitigation. Clim Risk Manag 16:145-163

60. Sathaye AJ, Christensen J, Lucon O, Denton F (2011) Renewable Energy in the Context of Sustainable Development. See discussions, stats, and author profiles for this publication at: https://www.researchgate.net/publication/307478000

61. Sawin JL, Sverrisson F, Leidreiter A (2016) Renewable Energy and Sustainable Development. Accounting for Impacts on the Path to $100 \%$ RE

62. Seid Yassin (2002) "Small-Scale Irrigation and Household Food Security: A Case Study of Three Irrigation Schemes in Gubalafto Woreda of North Wollo Zone, Amhara Region" Archived 2011-07-20 at the Wayback Machine, Master's Thesis, Graduate School of the University of Addis Ababa (June 2002), p. 35

63. Todd-Brown KEO, Randerson JT, Post WM, Hoffman FM, Tarnocai C, Schuur EAG, Allison SD (2013) Causes of variation in soil carbon simulations from CMIP5 Earth system models and comparison with observations, Biogeosciences, 10, 1717-1736, https://doi.org/10.5194/bg-10-1717-2013, 2013

64. Tucho TG, Nonhebel S (2017) Alternative energy supply system to a rural village in Ethiopia. Tucho and Nonhebel Energy, Sustainability and Society (2017) 7:33 DOI 10.1186/s13705-017-0136-x

65. Turmel M-S, Speratti A, Baudron F, Verhulst N, Govaerts B (2015) Crop residue management and soil health: A systems analysis. Agric Syst 134:6-16. doi:10.1016/j.agsy.2014.05.009

66. UN (United Nations) (2011) Res. 65/151. United Nations, New York, International Year of Sustainable Energy for All"

67. Renewable Energy Technologies for Rural Development. U UNCTAD (Current Studies On Science, Technology \& Innovation), N I T E D N A T I O N, S C O N F ER E N C E O N T R A, D E (2010) A N D D E V EL O P M EN T

68. UNEP (United Nation Environment Programme) (2019) Inquiry: Design of a Sustainable Financial System International Environment House Chemin des Anémones 11-13 Geneva, Switzerland

69. United Nations (2012a) United Nations Conference on Sustainable Development Outcome Document: The future we want. A/CONF.216/L.1 of 19 June 2012

70. Vezzoli C, Ceschin F, Osanjo L, M'Rithaa KM, Moalosi R, Nakazibwe V, Diehl JC (2018) Designing Sustainable Energy for All. Sustainable Product-Service System Design Applied to Distributed Renewable Energy. More information about this series at http://www.springer.com/series/8059

71. WCED (World Commission on Environment and Development) (1987) Our Common Future. Oxford University Press, Oxford

72. World Bank (1996) Rural Energy and Development: Improving Energy Supplies for Two Billion 37 People. Washington

73. World Bank (2000) Advancing gender equality. World Bank, Washington, DC

74. Yamane T (1967) Statistics: An Introductory Analysis, 2nd edn. Harper and Row, New York 
75. Tessama Z, Davis M, Tella PV, Lambe F (2013)Mainstreaming Sustainable Energy Access into National Development Planning: the Case of Ethiopia

\section{Figures}

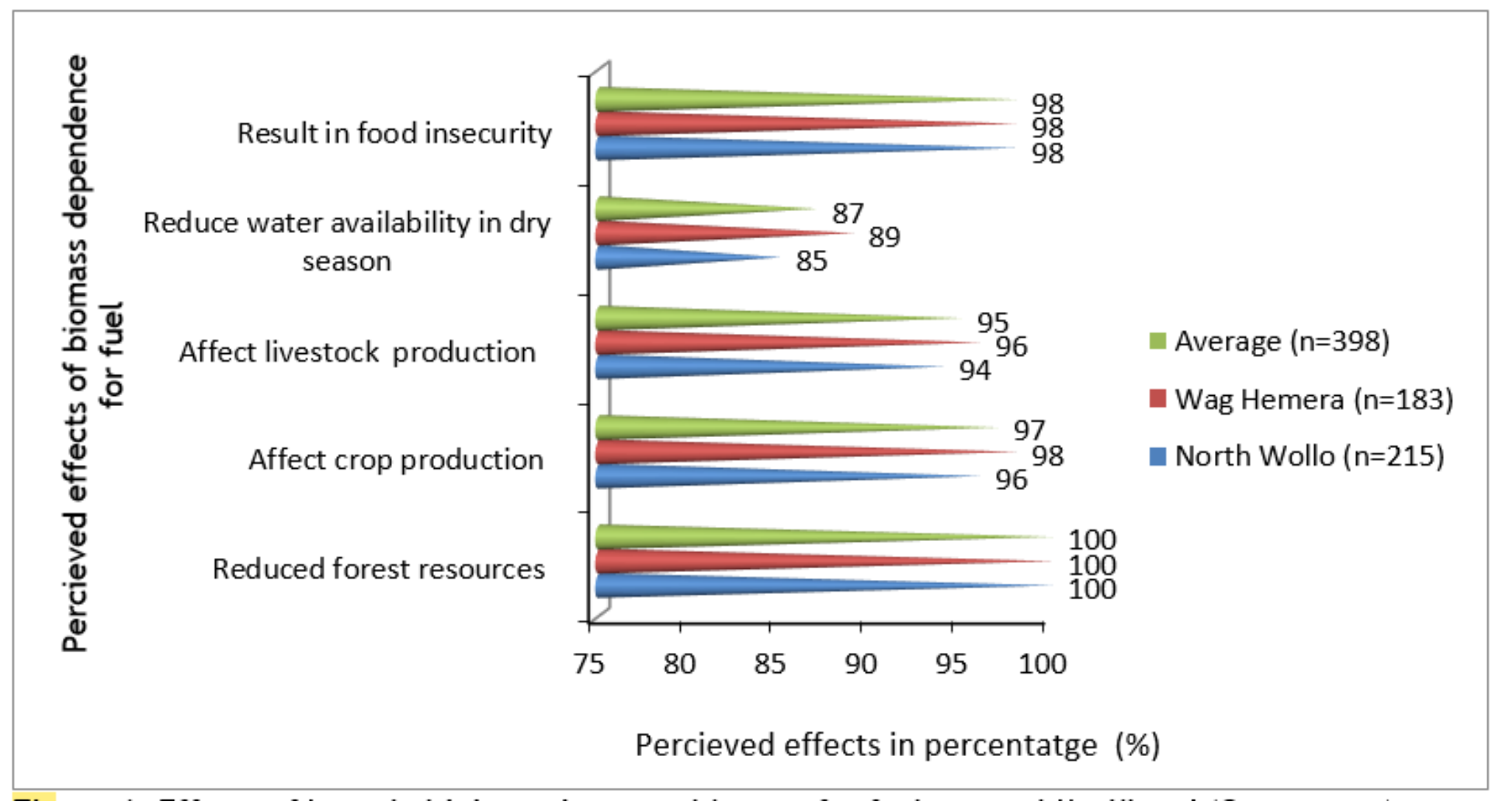

Figure 1

Effects of household dependence on biomass for fuel on rural livelihood (Own survey) 


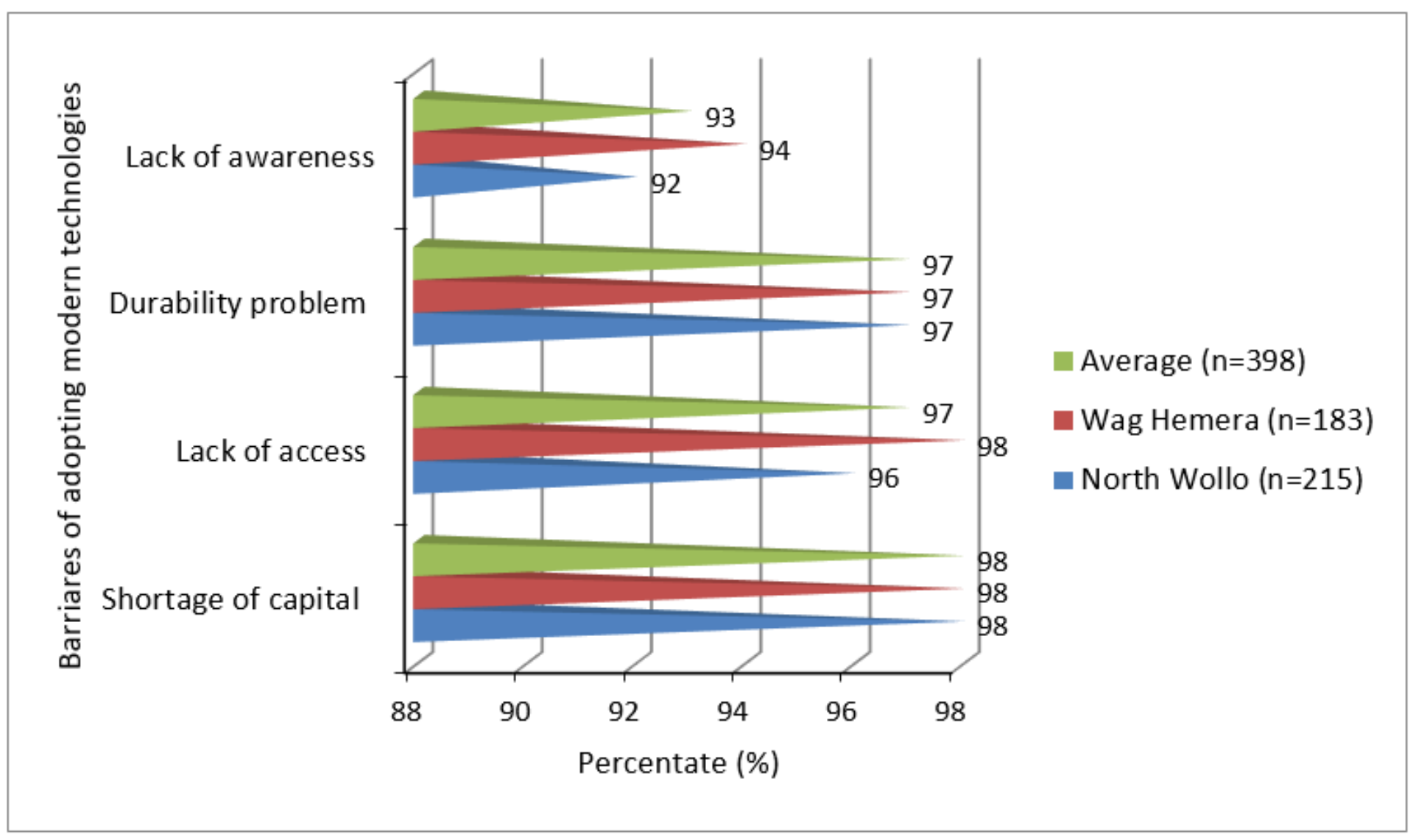

Figure 2

Barriers to adoption of modern energy technologies (Own survey) 